\title{
TRAFFIC FLOW ANALYSIS CONSIDERING THE EFFECTS OF FEATURES OF LEVEL CROSSING AND ROAD PASSERS
}

\author{
SHINGO NAKAGAWA \\ Signalling and Transport Information Technology Division, Railway Technical Research Institute, Japan
}

\begin{abstract}
At level crossings in urban area where trains and cars pass frequently, traffic jams are sometimes social issues. One way to improve this situation is to control and shorten the warning time of a level crossing by controlling train running. So far, several methods based on this idea have been proposed, however most of them aimed at shortening the active warning time, and they do not fully take into account the effect on the road traffic flow. On the basis of this situation, a traffic flow simulator has been developed which can consider the behavior of road passers including cars, bicycles and pedestrians within a level crossing area. The simulator can especially consider interaction among the road passers at a crowded level crossing, such as mutual avoidance behaviors. With this simulator, we conduct experimental calculations to evaluate how the traffic flow varies with factors, such as the size of the level crossing, active time of the warning bell and numbers and speed of road passers. This paper analyzes the results of the calculations and quantifies how the active warning time and the number of bicycles and pedestrians affect the car traffic capacity.
\end{abstract}

Keywords: level crossing, timetable, traffic capacity, avoidance behavior, experimental calculation.

\section{INTRODUCTION}

In Japan, level crossing accidents have been decreasing in recent years, but traffic jams at level crossings, as shown in Fig. 1, are still social issues, especially in urban area where trains and cars pass frequently. This problem reduces convenience for road passers and can lead to accidents. To control and shorten the warning time of a level crossing by controlling train running can be a solution to improve this situation [1]. Under such problem awareness, we have developed a traffic flow simulator which can consider the behavior of road passers within a level crossing area. This paper $d$ escribes the experimental calculations which we have conducted with this simulator. By analysing the results, we quantify how the active warning time and the number of bicycles and pedestrians affect the car traffic capacity.

\subsection{Abbreviations and terminologies}

In this article, we use some abbreviations and terminologies described as below:

- $\quad$ LC(s): level crossing(s).

- A LC: active when the level crossing's bells are ringing. It means that the active level crossing warns the road passers not to cross.

- TTLC: timetable of level crossing. It includes when the level crossing's bell starts to ring and when the gate arms start to descend, finish descending and start to ascend.

- TCC (of a level crossing): traffic capacity of cars. The number of cars which can pass a level crossing during certain time.

- Inside/outside of a LC: inside of a LC is the area surrounded by gate arms of the LC (regardless of state of the gate arms.) Other area is outside of the LC. In other words, all road passers are prohibited to be inside of a LC during the LC closes. 


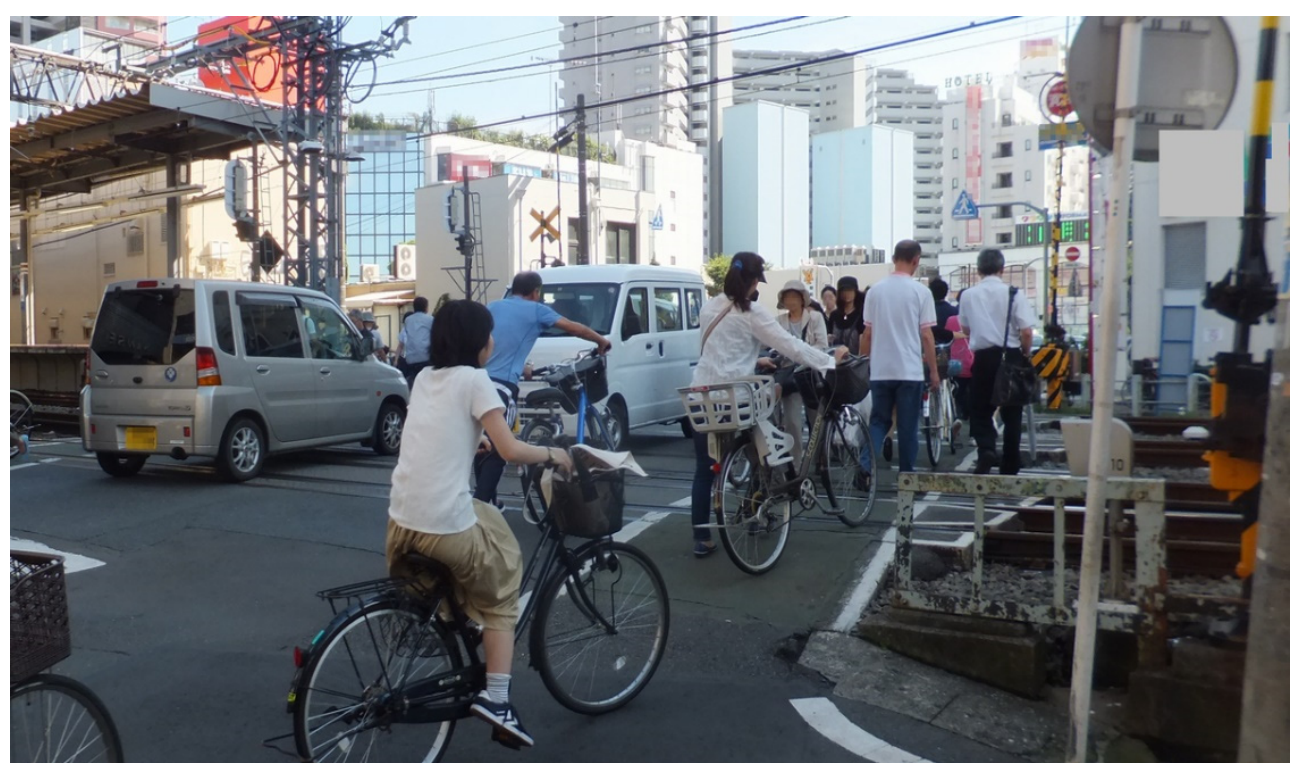

Figure 1: A crowded level crossing in Japan.

\section{TRAFFIC FLOW SIMULATOR AT A LEVEL CROSSING}

The screenshot of the traffic flow simulator we have developed is as shown in Fig. 2. It can simulate the behavior of road passers including cars, bicycles and pedestrians within a LC area, based on structure of the LC, the number of road passers and distribution of their speed and TTLC. The simulator calculates all road passers' position every 0.5 second as one step; it repeatedly simulates their behavior based on the previous step every 0.5 second.

All road passers basically go straight and cross the LC at their original constant speed; they also follow the rules described below.

- If they go straight and collide or get very close with other one, they take avoidance behavior; turning left or right, going diagonally or slowing down. If they cannot take any avoidance behavior, they stop and stay there.

- If pedestrians and bicycles are forced out to the car lane, they try to return sidewalk, if possible.

- When the LC activates, pedestrians and bicycles that are within the LC will take action either hurrying up or returning back to the outside of the LC. The rate of such road passers and the acceleration rate can be set by users.

- Some pedestrians and bicycles go into the LC, even if the LC is active. The rate of such road passers can be set by users.

- No road passers go into the completely closed LC.

The simulator calculates where each road passer is under these rules and output the results as CSV files. 


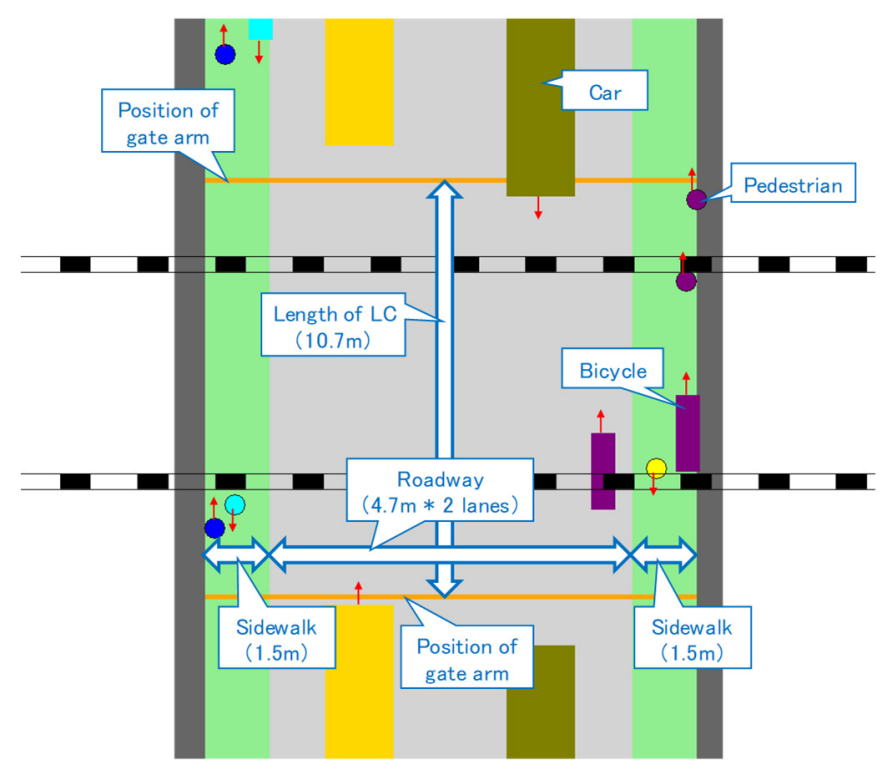

Figure 2: Example of a screenshot of the simulator. (Balloons, arrows and railways are added to the actual screenshot; Lengths in the figure are those of LC-A described later in Table 1.)

Table 1: Target LCs.

\begin{tabular}{|c|c|c|c|}
\hline & Car Tracks & Sidewalks & Length \\
\hline LC-A & $4.7 \mathrm{~m}$ width, 2 lanes & $1.5 \mathrm{~m}$ width, 2 lanes & $10.7 \mathrm{~m}$ \\
\hline LC-B & $4.0 \mathrm{~m}$ width, 2 lanes & $1.4 \mathrm{~m}$ width, 2 lanes & $16.2 \mathrm{~m}$ \\
\hline LC-C & $3.9 \mathrm{~m}$ width, 2 lanes & $1.7 \mathrm{~m}$ width, 2 lanes & $10.9 \mathrm{~m}$ \\
\hline LC-D & $\begin{array}{c}2.8 \mathrm{~m} \text { width, 1 lane } \\
\text { (One-way traffic) }\end{array}$ & $0.9 \mathrm{~m}$ width, 1 lane & $11.8 \mathrm{~m}$ \\
\hline
\end{tabular}

3 OUTLINE OF EXPERIMENTAL CALCULATION

\subsection{Target level crossings}

We choose four LCs as the targets of experiment, as described in Table 1. All of them are based on but not exactly same as the real LCs in Tokyo metropolitan area, because a railway line and a road cross diagonally at these LCs. Our simulator cannot deal with such LCs so that on our experiment we regard they cross vertically at the target LCs.

At LC-A, B and C, there are two car lanes (single lane for traffic in both directions) and two sidewalks, as shown in Fig. 2. LC-D is one-way traffic for cars so that there are one car track and one sidewalk, which are narrower than those of LC-A, B and C.

LC-B is expected to be more crowded than LC-A, because LC-B is narrower and the length is longer than LC-A. With respect to LC-C, car tracks are narrower and sidewalks are wider than LC-A and $\mathrm{B}$, therefore it is difficult to predict the grade of congestion compared to LC-A. LC-D has only one car lane and is narrower than other LCs, therefore TCC at LC-D is estimated to be less than half of those at other LCs. 


\subsection{Premises and parameters of our calculation}

1. Common settings throughout all calculation

- Simulation time is 5 minutes.

- Cars arrive the LC continuously. The number of cars which can cross over the LC in simulation time is regarded as TCC.

- Bicycles and pedestrians basically follow inside the sidewalk but may walk or run inside the car tracks if needed.

2. Number of pedestrians

One of five cases shown in Table 2 is applied to each calculation. They are total number of pedestrians who come to the LC in the simulation time (five minutes) per a sidewalk. For example, on case 1, 40 pedestrians appear at LC-A, B and C and 20 at LC-D. All of them appear randomly. Note that on case 5 at LC-D, there are 30 pedestrians in the same direction as that of cars and 10 in the opposite direction.

3. Number of bicycles

One of two cases shown in Table 3 is applied to each calculation. Meanings of these numbers are same as those of pedestrian.

4. Original speed of road passer

We assume that there are 10 types of pedestrians whose speed are different. On our calculation, one of four cases shown in Table 4, which are different in terms of the component ratio of these 10 types, is applied. On the basis of a multiple regression analysis described in Suzuki et al. [2] and considering that LC-B is longer than other LCs, we determined median speed of pedestrian $140 \mathrm{~cm} / \mathrm{s}$ at LC-B and $135 \mathrm{~cm} / \mathrm{s}$ at the rest LCs.

Regarding bicycles, 10 speeds are set in the same way as pedestrian and one of four cases is applied to each calculation.

Case 1 is uniform distribution. Case 2/3 is the case whose average speed is fast/slow.

Note that the original speed of cars is uniformly $530 \mathrm{~cm} / \mathrm{s}$.

Table 2: The number of pedestrians per one sidewalk.

\begin{tabular}{|l|l|}
\hline & \multicolumn{1}{|c|}{ Number of pedestrians per one sidewalk } \\
\hline Case 1 & 10 in each direction \\
\hline Case 2 & 20 in each direction \\
\hline Case 3 & 30 in each direction \\
\hline Case 4 & 40 in each direction \\
\hline Case 5 & $\begin{array}{l}30 \text { in one direction, } \\
10 \text { in the opposit direction }\end{array}$ \\
\hline
\end{tabular}

Table 3: The number of bicycles per one sidewalk.

\begin{tabular}{|c|l|}
\hline & \multicolumn{1}{|c|}{ Number of bicycles per one sidewalk } \\
\hline Case 1 & 10 in each direction \\
\hline Case 2 & 20 in each direction \\
\hline
\end{tabular}


5. Behavior selection of the road passer when LC is activated while the passers are crossing

When a LC starts warning, some road passers can be within the LC. Then they will change their behavior. On our calculation, three choices of their behavior are assumed: hurrying up, returning back and waiting at outside of the gate arm and keeping their previous behavior unchanged. Regarding the selection rate, one of two cases shown in Tables 5 and 6 is applied to each calculation.

It is natural that these rates vary depending on the positions of the road passers in the inside of the LC. For example, when they are almost going through the LC, they will not return back because passing through the LC is obviously safer for them than returning. For this reason, applied selection rates change depending on the positions of the passers.

Note that cars choose to always keep going, because to accelerate or to return is illegal or dangerous for them.

Table 4: The composition ratio of original speed of pedestrian and bicycle.

\begin{tabular}{|c|c|c|c|c|c|c|}
\hline $\begin{array}{l}\text { Pedestrian (LC-A, } \\
\text { C and D) (cm/s) }\end{array}$ & $\begin{array}{l}\text { Pedestrian } \\
(\mathrm{LC}-\mathrm{B})(\mathrm{cm} / \mathrm{s})\end{array}$ & $\begin{array}{c}\text { Bicycle } \\
(\mathrm{cm} / \mathrm{s})\end{array}$ & Case 1 & Case 2 & Case 3 & Case 4 \\
\hline 180 & 185 & 410 & $10 \%$ & $20 \%$ & - & $20 \%$ \\
\hline 170 & 175 & 390 & $10 \%$ & $10 \%$ & $10 \%$ & - \\
\hline 160 & 165 & 370 & $10 \%$ & $20 \%$ & - & $20 \%$ \\
\hline 150 & 155 & 350 & $10 \%$ & $20 \%$ & - & - \\
\hline 140 & 145 & 330 & $10 \%$ & $10 \%$ & $10 \%$ & $10 \%$ \\
\hline 130 & 135 & 310 & $10 \%$ & $10 \%$ & $10 \%$ & $10 \%$ \\
\hline 120 & 125 & 290 & $10 \%$ & - & $20 \%$ & - \\
\hline 110 & 115 & 270 & $10 \%$ & - & $20 \%$ & $20 \%$ \\
\hline 100 & 105 & 250 & $10 \%$ & $10 \%$ & $10 \%$ & - \\
\hline 90 & 95 & 230 & $10 \%$ & - & $20 \%$ & $20 \%$ \\
\hline
\end{tabular}

Table 5: Behavior selection of the road passer when LC start to warn. (When the road passer has moved $20 \%$ or less of the LC's length.)

\begin{tabular}{|l|l|l|}
\hline & \multicolumn{1}{|c|}{ Pedestrian } & \multicolumn{1}{c|}{ Bicycle } \\
\hline \multirow{3}{*}{ Case 1 } & Hurry: $50 \%$ & Hurry: $10 \%$ \\
& Return: $20 \%$ & Return: $20 \%$ \\
& Keep going: $30 \%$ & Keep going: $70 \%$ \\
\hline \multirow{3}{*}{ Case 2} & Hurry: $30 \%$ & \\
& Return: $20 \%$ & Return: $20 \%$ \\
& Keep going: $50 \%$ & Keep going: $80 \%$ \\
\hline
\end{tabular}

Table 6: Behavior selection of the road passer when LC start to warn. (When the road passer has moved more than $20 \%$ of the LC's length.)

\begin{tabular}{|l|l|l|}
\hline & \multicolumn{1}{|c|}{ Pedestrian } & \multicolumn{1}{c|}{ Bicycle } \\
\hline \multirow{2}{*}{ Case 1} & $\begin{array}{l}\text { Hurry: } 50 \% \\
\text { Keep going: } 50 \%\end{array}$ & $\begin{array}{l}\text { Hurry: } 10 \% \\
\text { Keep going: } 90 \%\end{array}$ \\
\hline \multirow{2}{*}{ Case 2} & $\begin{array}{l}\text { Hurry: } 30 \% \\
\text { Keep going: } 70 \%\end{array}$ & Keep going: $100 \%$ \\
\hline
\end{tabular}


Table 7: The rate of pedestrians and bicycles who go into the LC after its bell starts ringing.

\begin{tabular}{|c|c|c|}
\hline & $\begin{array}{l}\text { While the bell are ringing (before the gate } \\
\text { arms start to descend) }\end{array}$ & $\begin{array}{l}\text { While the gate arms are } \\
\text { descending }\end{array}$ \\
\hline Case 1 & $30 \%$ & $10 \%$ \\
\hline Case 2 & $\begin{array}{l}\text { For pedestrians and bicycles whose original } \\
\text { speed are: } \\
\text { - } \quad \text { fast: } 70 \% \\
\text { - } \quad \text { medium: } 50 \% \\
\text { - } \quad \text { slow: } 30 \%\end{array}$ & $10 \%$ \\
\hline
\end{tabular}

6. Penetration inside active $\mathrm{LC}$

While a LC is warning, road passers should not start to cross; they have to stop at in front of the gate arm. However, some of them who are in hurry go into the LC which has not been completely shut by the gate. Regarding the rate of such pedestrians and bicycles, one of two cases shown in Table 7 is applied to each calculation. In case 2, the rate for faster pedestrians is set to be higher, because they tend to think they can pass through the LC before the gates shut.

Note that cars do not go into active LC. In addition, after the gates are completely shut, no road passers including pedestrians and bicycles go into the LC.

7. TTLC (timetable of level crossing)

We define 10 TTLCs shown in Fig. 3. One of them is applied to each calculation. In all TTLCs, the LC closes once or twice for five minutes and each closure time is 40 or 70 seconds. Therefore total closure time is 40 seconds at the shortest and 140 seconds at the longest (see Table 8). The bell of the LC starts to ring four seconds before when the gate arms start to descend taking 12 seconds; in other words, the LC activates 16 seconds before its closure. After the closure, the gate arms ascend in three seconds.

As described in (6), pedestrians and bicycles go into the inside of the LC unless it is completely shut. So the time they cannot go into the $\mathrm{LC}$ is 40 or 70 seconds per closure. For cars, the time is 56 or 86 seconds, because they cannot go into the LC after it activates.

We conducted our experiments with 1600 settings, which are the combinations of the cases described in (2)-(7). We conducted five calculations under each of 1600 settings for each of four LCs listed in 3.1; in other words, we conducted totally 32000 calculations.

\subsection{Propriety of the simulations}

Rules of behavior of road passers described in Section 2 and parameters described in 3.2 are defined to depict natural behavior inside the LC. To check the propriety of them, we compared the results of our calculation to behavior within real LC.

We have recorded the traffic at LC-B. From this video, each pedestrian's walking distance in 0.5 second is measured. We also obtain such walking distance from our calculation regarding LC-B. Note that the target of comparison is right after the LC opens, when the congestion occurs.

The results are shown in Table 9. Differences of average for both directions are only about $1 \mathrm{~cm}$, which do not matter. On the other hand, standard deviations of results of our simulation are larger than those of real LC. On our simulation, $8 \%$ of the obtained data do not go forward due to the congestion; they walk aside or stop. To revise the rule to make them walk forward or diagonal may reduce the standard deviation. 

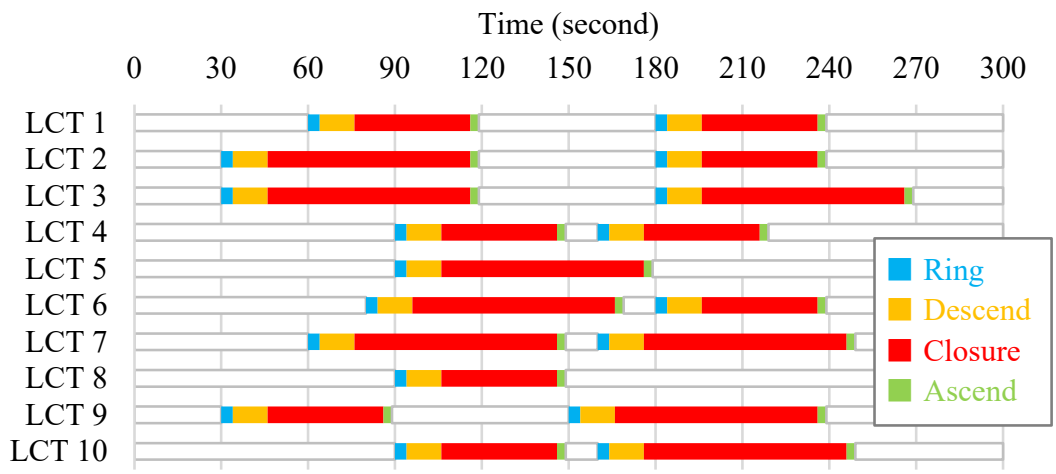

Figure 3: Timetables of level crossing.

Table 8: Closure time of each TTLC.

\begin{tabular}{|c|c|c|c|c|}
\hline & \multicolumn{3}{|c|}{ Closure time (second) } & \multirow{2}{*}{$\begin{array}{l}\text { Interval } \\
\text { (second) }\end{array}$} \\
\hline & Total & 1st closure & 2nd closure & \\
\hline TTLC 3 & 140 & 70 & 70 & 61 \\
\hline TTLC 7 & 140 & 70 & 70 & 11 \\
\hline TTLC 2 & 110 & 70 & 40 & 61 \\
\hline TTLC 6 & 110 & 70 & 40 & 11 \\
\hline TTLC 9 & 110 & 40 & 70 & 61 \\
\hline TTLC 10 & 110 & 40 & 70 & 11 \\
\hline TTLC 1 & 80 & 40 & 40 & 61 \\
\hline TTLC 4 & 80 & 40 & 40 & 11 \\
\hline TTLC 5 & 70 & 70 & - & - \\
\hline TTLC 8 & 40 & 40 & - & - \\
\hline
\end{tabular}

Interval is the duration from the gate arms finish to ascend to the bell starts to ring again, which is painted white between two closures in Fig. 3.

Table 9: Walking distance of pedestrian in 0.5 second.

\begin{tabular}{|c||c||c|c|c|c|}
\hline \multicolumn{1}{|c||}{} & \multirow{2}{*}{$\begin{array}{c}\text { Number } \\
\text { of data }\end{array}$} & \multicolumn{2}{|c|}{ Direction of travel $(\mathrm{cm})$} & \multicolumn{2}{c|}{ Lateral direction $(\mathrm{cm})$} \\
\cline { 3 - 6 } & 13848 & 51.9 & 16.6 & 8.3 & 7.7 \\
\hline \hline $\begin{array}{c}\text { Recorded } \\
\text { video }\end{array}$ & 138 deviation & Average & $\begin{array}{c}\text { Standard } \\
\text { deviation }\end{array}$ \\
\hline Simulation & 34523 & 53.2 & 23.9 & 9.2 & 17.6 \\
\hline
\end{tabular}




\section{ANALYSIS ON TRAFFIC CAPACITY OF CARS}

\subsection{Analysis for LC-A}

As described in Section 3.2, 8000 calculations have been conducted for LC-A. The distribution of TCC obtained in these calculations is shown in Fig. 4. They ranged from 18 to 140 and their average is 90.2 . The distribution has five peaks and does not resemble to normal distribution, about which we will consider latter section.

Note that in some calculations a very small number of TCC is obtained. It is because heavy congestion has occurred just after the LC has opened and some road passers obstruct other people each other. Such passers block the car lanes. In a real situation, under such congestion, each road passers settle the matter by mutual concessions, such as walking back to let other people go. These results show that our simulator cannot perform such cooperation, which is our future issue.

Table 10 shows the summarization of obtained TCC classified by each parameter. The difference of TCC due to TTLC is larger than other factors. Five peaks observed in Fig. 4 are almost same as average TCC under each TTLC. Among the TTLCs whose total closure time are same, average TCC under them are almost the same. We can say that the TTLC affects TCC mostly and the number of pedestrians and bicycles also makes some difference to TCC. Other parameters have only little effect.

We conducted significance tests to obtained TCC; checking whether or not the obtained TCC have significantly different among each case/TTLC. The results are shown in Table 11. We conducted the tests for pairs of case/TTLC; for example, "case 1\&2" compares the TCC obtained under case 1 and under case 2.

Significant differences due to the number of pedestrians, the number of bicycles and the original speed are observed. Furthermore, regarding TTLC, the p-value is less than 0.01 for 41 out of 45 pairs. The remaining four are the pairs of TTLC whose total closure time are same, but some of the pairs which have such relation are included in the 41 pairs mentioned above. We can also say that for all the pairs of TTLC whose total closure time are same, more TCC has obtained under the TTLC whose interval of two closures is shorter. The reason for these different is not clear, but it is presumed that to make the closure time closer and open the LC continuously may lead the traffic flow smoothly and effective to increase the TCC (note that to shorten the closure time is obviously more effective).

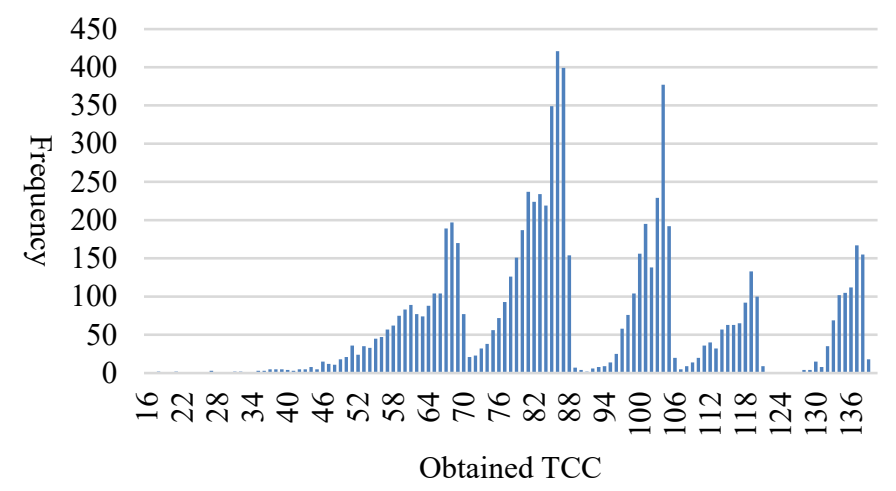

Figure 4: Distribution of obtained TCC at LC-A. 
Table 10: The obtained TCC at LC-A classified by case/TTLC.

\begin{tabular}{|c|c|c|c|c|}
\hline \multirow{2}{*}{ Parameters } & \multirow{2}{*}{ Case/TTLC } & \multicolumn{3}{|c|}{ TCC } \\
\hline & & Average & Max. & Min. \\
\hline \multirow{5}{*}{ Number of pedestrians } & Case 1 & 92.5 & 139 & 27 \\
\hline & Case 2 & 91.0 & 139 & 35 \\
\hline & Case 3 & 89.3 & 139 & 24 \\
\hline & Case 4 & 87.2 & 140 & 18 \\
\hline & Case 5 & 91.0 & 139 & 32 \\
\hline \multirow{2}{*}{ Number of bicycles } & Case 1 & 93.9 & 140 & 42 \\
\hline & Case 2 & 86.4 & 137 & 18 \\
\hline \multirow{4}{*}{ Original speed } & Case 1 & 90.2 & 139 & 18 \\
\hline & Case 2 & 91.3 & 140 & 25 \\
\hline & Case 3 & 89.3 & 139 & 18 \\
\hline & Case 4 & 89.9 & 139 & 21 \\
\hline \multirow{2}{*}{$\begin{array}{c}\text { Behavior selection when } \\
\text { LC activates }\end{array}$} & Case 1 & 90.2 & 140 & 21 \\
\hline & Case 2 & 90.1 & 139 & 18 \\
\hline \multirow{2}{*}{ Penetration into active LC } & Case 1 & 90.1 & 139 & 18 \\
\hline & Case 2 & 90.2 & 140 & 18 \\
\hline \multirow{10}{*}{ TTLC } & TTLC 1 & 101.4 & 107 & 66 \\
\hline & TTLC 2 & 80.6 & 88 & 38 \\
\hline & TTLC 3 & 61.2 & 71 & 18 \\
\hline & TTLC 4 & 101.8 & 106 & 62 \\
\hline & TTLC 5 & 113.4 & 121 & 50 \\
\hline & TTLC 6 & 83.2 & 89 & 50 \\
\hline & TTLC 7 & 62.7 & 71 & 36 \\
\hline & TTLC 8 & 135.3 & 140 & 51 \\
\hline & TTLC 9 & 80.8 & 88 & 18 \\
\hline & TTLC 10 & 81.5 & 89 & 55 \\
\hline
\end{tabular}

Table 11: The results of significance test among each case/TTLC.

\begin{tabular}{|c|c|c|}
\hline Parameters & Significance & Pair of cases/TTLCs \\
\hline \multirow{3}{*}{ Number of pedestrians } & $p \leq 0.01 * *$ & Case $1 \& 3,1 \& 4,2 \& 4,4 \& 5$ \\
\hline & $p \leq 0.05^{*}$ & Case $2 \& 3,3 \& 4,3 \& 5$ \\
\hline & $p>0.05$ & Case $1 \& 2,1 \& 5,2 \& 5$ \\
\hline Number of bicycles & $p \leq 0.01 * *$ & Case $1 \& 2$ \\
\hline \multirow{3}{*}{ Original speed } & $p \leq 0.01^{* *}$ & Case $2 \& 3$ \\
\hline & $p \leq 0.05^{*}$ & Case $2 \& 4$ \\
\hline & $p>0.05$ & Case $1 \& 2,1 \& 3,1 \& 4,3 \& 4$ \\
\hline $\begin{array}{l}\text { Behavior selection when LC } \\
\text { activates }\end{array}$ & $p>0.05$ & Case $1 \& 2$ \\
\hline Penetration into active $\mathrm{LC}$ & $p>0.05$ & Case $1 \& 2$ \\
\hline \multirow{3}{*}{ TTLC } & $p \leq 0.01 * *$ & 41 pairs (all pairs except the following) \\
\hline & $p \leq 0.05^{*}$ & TTLC $2 \& 10,9 \& 10$ \\
\hline & $p>0.05$ & TTLC $1 \& 4,2 \& 9$ \\
\hline
\end{tabular}


Table 12: Average of obtained TCC at each LC.

\begin{tabular}{|c|c|c|c|c|c|}
\hline Parameter & Case/TTLC & LC-A & LC-B & $\mathrm{LC}-\mathrm{C}$ & LC-D \\
\hline \multirow{5}{*}{ Number of pedestrians } & Case 1 & 92.5 & 87.1 & 86.2 & 37.0 \\
\hline & Case 2 & 91.0 & 85.6 & 84.1 & 34.0 \\
\hline & Case 3 & 89.3 & 83.3 & 81.8 & 31.0 \\
\hline & Case 4 & 87.2 & 80.6 & 79.0 & 28.6 \\
\hline & Case 5 & 91.0 & 85.3 & 84.2 & 35.6 \\
\hline \multirow{2}{*}{ Number of bicycles } & Case 1 & 93.9 & 88.4 & 87.2 & 39.1 \\
\hline & Case 2 & 86.4 & 80.4 & 78.9 & 27.3 \\
\hline \multirow{4}{*}{ Original speed } & Case 1 & 90.2 & 84.7 & 83.2 & 33.3 \\
\hline & Case 2 & 91.3 & 85.3 & 84.2 & 35.5 \\
\hline & Case 3 & 89.3 & 83.3 & 81.8 & 31.4 \\
\hline & Case 4 & 89.9 & 84.3 & 83.1 & 32.7 \\
\hline \multirow{2}{*}{$\begin{array}{l}\text { Behavior selection } \\
\text { when LC activates }\end{array}$} & Case 1 & 90.2 & 84.4 & 83.0 & 33.4 \\
\hline & Case 2 & 90.1 & 84.4 & 83.1 & 33.1 \\
\hline \multirow{2}{*}{$\begin{array}{c}\text { Penetration into active } \\
\text { LC }\end{array}$} & Case 1 & 90.1 & 84.4 & 82.9 & 33.3 \\
\hline & Case 2 & 90.2 & 84.4 & 83.1 & 33.2 \\
\hline \multirow{10}{*}{ TTLC } & TTLC 1 & 101.4 & 96.1 & 94.5 & 39.4 \\
\hline & TTLC 2 & 80.6 & 75.0 & 74.1 & 25.3 \\
\hline & TTLC 3 & 61.2 & 56.2 & 55.5 & 18.0 \\
\hline & TTLC 4 & 101.8 & 95.9 & 94.8 & 41.4 \\
\hline & TTLC 5 & 113.4 & 104.7 & 102.6 & 40.0 \\
\hline & TTLC 6 & 83.2 & 78.5 & 77.0 & 32.6 \\
\hline & TTLC 7 & 62.7 & 59.0 & 57.2 & 22.2 \\
\hline & TTLC 8 & 135.3 & 126.4 & 125.3 & 54.6 \\
\hline & TTLC 9 & 80.8 & 75.6 & 74.5 & 27.0 \\
\hline & TTLC 10 & 81.5 & 76.4 & 75.0 & 31.7 \\
\hline
\end{tabular}

\subsection{Comparison of four LCs}

The average TCC at four LCs are shown in Table 12. The obtained TCC are in the order of LC-A $>B>C>D$ for all of 25 parameters. Obtained TCC on LC-D are less than half of those on other LCs, as we have estimated in 3.1. The trends of difference between the obtained TCC under each parameter are almost same on all LCs.

\subsection{Regression analysis on TCC}

We examined multiple regression analysis to obtain regression formula which explains TCC by using parameters described above as descriptive variables. We set 22 dummy variables which are correspond to each parameter as candidate of descriptive variables and apply forward-backward stepwise selection method for variable selection. Note that each of "number of bicycles," "behavior selection when LC activates" and "penetration into active LC" can be expressed by one dummy variable, because there are only two selections.

The results are shown in Table 13. Selected variables and their significances are almost the same through all LCs. 
Table 13: Obtained regression formula which explains TCC.

\begin{tabular}{|c|c|c|c|c|c|c|c|c|c|}
\hline Parameter & Case/TTLC & LC- & $\mathrm{A}$ & LC- & $\mathrm{B}$ & LC- & $\mathrm{C}$ & LC- & $\mathrm{D}$ \\
\hline (Constant term) & & 81.97 & *** & 76.51 & *** & 75.17 & *** & 32.42 & ** \\
\hline \multirow{5}{*}{$\begin{array}{l}\text { Number of } \\
\text { pedestrians }\end{array}$} & Case 1 & 5.29 & $* *$ & 6.55 & $* *$ & 7.20 & $* *$ & 8.39 & ** \\
\hline & Case 2 & 3.87 & $* *$ & 5.00 & $* *$ & 5.10 & $* *$ & 5.40 & $* *$ \\
\hline & Case 3 & 2.12 & $* *$ & 2.77 & $* *$ & 2.81 & $* *$ & 2.46 & $* *$ \\
\hline & Case 4 & - & & - & & - & & - & \\
\hline & Case 5 & 3.82 & $* *$ & 4.73 & $* *$ & 5.22 & $* *$ & 6.99 & $* *$ \\
\hline $\begin{array}{l}\text { Number of } \\
\text { bicycles }\end{array}$ & Case 2 & -7.51 & $* *$ & -8.01 & ** & -8.33 & ** & -11.83 & $* *$ \\
\hline \multirow{4}{*}{ Original speed } & Case 1 & 0.30 & & 0.41 & $*$ & - & & 0.67 & $*$ \\
\hline & Case 2 & 1.42 & $* *$ & 0.99 & $* *$ & 1.07 & ** & 2.86 & ** \\
\hline & Case 3 & -0.63 & $* *$ & -0.98 & $* *$ & -1.41 & ** & -1.21 & ** \\
\hline & Case 4 & - & & - & & - & & - & \\
\hline $\begin{array}{l}\text { Behavior selection } \\
\text { when LC activates }\end{array}$ & Case 2 & - & & - & & - & & - & \\
\hline $\begin{array}{c}\text { Penetration into } \\
\text { active LC }\end{array}$ & Case 2 & - & & - & & - & & - & \\
\hline \multirow{10}{*}{ TTLC } & TTLC 1 & 19.93 & $* *$ & 19.65 & $* *$ & 19.50 & $* *$ & 7.66 & $* *$ \\
\hline & TTLC 2 & -0.91 & $* *$ & -1.38 & $* *$ & -0.92 & $* *$ & -6.40 & $* *$ \\
\hline & TTLC 3 & -20.36 & $* *$ & -20.21 & ** & -19.46 & $* *$ & -13.71 & ** \\
\hline & TTLC 4 & 20.26 & $* *$ & 19.44 & $* *$ & 19.79 & ** & 9.70 & ** \\
\hline & TTLC 5 & 31.92 & $* *$ & 28.25 & $* *$ & 27.59 & $* *$ & 8.24 & $* *$ \\
\hline & TTLC 6 & 1.69 & $* *$ & 2.06 & $* *$ & 2.04 & ** & 0.90 & * \\
\hline & TTLC 7 & -18.81 & $* *$ & -17.43 & $* *$ & -17.82 & ** & -9.58 & ** \\
\hline & TTLC 8 & 53.76 & $* *$ & 50.03 & $* *$ & 50.33 & $* *$ & 22.90 & $* *$ \\
\hline & TTLC 9 & -0.76 & $* *$ & -0.79 & * & -0.52 & & -4.76 & ** \\
\hline & TTLC 10 & - & & - & & - & & - & \\
\hline Adjusted $\mathrm{R}^{2}$ & & 0.94 & & 0.91 & & 0.90 & & 0.65 & \\
\hline
\end{tabular}

The mark ** and * mean the significance of selected variables, whose meanings are same as those of Table 11. The mark - means the variable is not selected.

As for LC-A, B and C (i.e. LCs with two car lanes,) coefficients for each variable are almost the same. It means that differences of constant terms correspond to those of obtained TCC. Coefficients of determination (adjusted $\mathrm{R}^{2}$ ) are over 0.90 for these LCs, which show the obtained regression formulas are appropriate.

Regarding LC-D, constant term is less than those of other LCs because it has only one car lane. Magnitude relationship of coefficients is slightly different from that of other LCs, while their signs are same as those of other LCs. But the adjusted $\mathrm{R}^{2}$ is 0.65 , which means less appropriate than others.

Next, to estimate the effect of shortening the active time of the LC, we tried to obtain regression formula which explains TCC by using the time car can go through the LC (i.e. 300 seconds - active time of the LC) as descriptive variables. The formula is as eqn (1) below, where $y$ is obtained TCC, $x$ is the time and $\alpha, \beta$ are coefficients.

$$
y=\alpha x+\beta \text {. }
$$

The results are shown in Table 14. As for LC-A, B and C, adjusted $\mathrm{R}^{2}$ is sufficiently large and all $\alpha, \beta$ are sufficiently significant, which mean obtained formulas are appropriate. Note that all $\alpha$ are about 0.6. It means that if the time the car can go through the LC extends one second, the TCC will increase about 0.6 . This result is well match with the previous paper by 
Iwasaki et al. [3], which estimates the traffic capacity of cars at the LC with straight road as about 1000 per an hour and one car lane.

Regarding LC-D, $\alpha$ is about half of $\alpha$ for other LCs and $\alpha, \beta$ are sufficiently significant, both of which are reasonable result. But considering the adjusted $\mathrm{R}^{2}$, this formula has weak propriety.

Table 14: The estimated relationship between the TCC and the time car can go through the LC.

\begin{tabular}{|c||c|c|c|c|}
\hline & LC-A & LC-B & LC-C & LC-D \\
\hline \hline$\alpha$ (coefficient for the time) & 0.624 & 0.582 & 0.580 & 0.284 \\
\hline$\beta$ (constant term) & -17.26 & -15.90 & -16.84 & -15.64 \\
\hline \hline Adjusted $\mathrm{R}^{2}$ & 0.90 & 0.86 & 0.84 & 0.41 \\
\hline All $\alpha, \beta$ are sufficiently significant $\left(p \leq 0.01^{* *}\right)$.
\end{tabular}

\section{CONCLUSION}

We have described about our traffic flow simulator and the experimental calculations to evaluate how the traffic flow varies with factors, such as the size of the level crossing, active time of the warning bell and numbers and speed of road passers. By analysing the results, we can show that the active warning time of level crossing affects the traffic capacity of cars, whose effect is about $0.6 \mathrm{car} / \mathrm{second}$ at level crossing with two car lanes. We also show that the number of pedestrians and bicycles and pedestrians affect traffic capacity of cars significantly. Moreover, it is suggested that making the closure time of level crossing closer and opening the level crossing continuously may lead the traffic flow smoothly and effective to increase the traffic capacity of cars. Note that this may force road passers to wait longer and reduce convenience and safety.

From our calculation, we also analysed the number of pedestrians who are left inside the closed level crossing. But we could not obtain significant regression formula. The main reason is considered the obstruction described in 4.1. We aim to depict the road passers' behavior more precise and improve the validity of evaluation to solve these problems including we show in this paper.

\section{REFERENCES}

[1] Fukuda, M., Study of the control method for Level Crossing with CBTC System in case of train delay and congested traffic. IEE Japan, pp. 1-6, 2014, (in Japanese).

[2] Suzuki, D., Endoh, H., Saito, A., Akiu, N. \& Mizukami, N., Effects on walking velocity by length, warning and congestion of railroad crossing, Proceedings of the $59^{\text {th }}$ Conference of Japan Ergonomics Society, 2018, (in Japanese).

[3] Iwasaki, M., Watanabe, T. and Miyazawa, T., Traffic flow characteristics and delay at urban railroad crossings. Proceedings of Japan Society of Civil Engineers, 401, pp. 61-67, 1989, (in Japanese). 